Check for updates

Cite this: RSC Adv., 2018, 8, 36063

Received 27th July 2018

Accepted 6th October 2018

DOI: 10.1039/c8ra06346j

rsc.li/rsc-advances

\section{Magnetic-propelled $\mathrm{Fe}_{3} \mathrm{O}_{4}$-chitosan carriers enhance L-asparaginase catalytic activity: a promising strategy for enzyme immobilization}

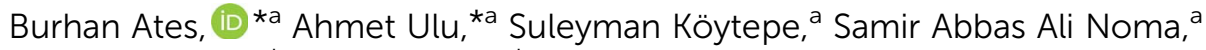 \\ Veli Serkan Kolat ${ }^{\mathrm{b}}$ and Tekin Izgi $^{\mathrm{b}}$
}

Magnetic-propelled carriers comprising magnetic $\mathrm{Fe}_{3} \mathrm{O}_{4}$-chitosan nanoparticles were immobilized with Lasparaginase (L-ASNase). The enzyme displayed enhanced catalytic activity in a weak magnetic field, and thermal and $\mathrm{pH}$ stabilities. The conjugated L-ASNase presented higher thermostability and wider range of $\mathrm{pH}$ stability in comparison with those of free L-ASNase. Moreover, the reusability of conjugated L-ASNase significantly improved after immobilization and it retained $60.5 \%$ of its initial activity after undergoing 16 cycles. The conjugated L-ASNase maintained more than $50 \%$ and $48 \%$ initial activity after 4 weeks of storage at $4{ }^{\circ} \mathrm{C}$ and room temperature, respectively. Furthermore, we reveal that the activity of conjugated L-ASNase onto magnetic $\mathrm{Fe}_{3} \mathrm{O}_{4}$-chitosan particles increased by about 3-fold in the weak magnetic field at certain frequencies and flux density compared with that of free L-ASNase. Considering these excellent attributes, the magnetic-propelled mechanism in the transporting and activation of LASNase can be used by enhancing the catalytic activity, stability, and efficiency in vital implications for medicinal biotechnology.

\section{Introduction}

L-Asparagine (L-Asn) is an essential amino acid for the growth of tumor cells. Cancer cells must absorb this amino acid from the bloodstream in order to synthesize protein and grow. L-ASNase (asparagine amidohydrolase, EC 3.5.1.1) catalyzes the hydrolysis of L-Asn to aspartic acid and ammonia. ${ }^{1}$ At the end of this enzymatic hydrolysis, the cancer cells grow slowly and they die. L-ASNase is one of the most widely used chemotherapeutic agent in the treatment of many cancer types. ${ }^{2,3}$ It is also an important enzyme in the food industry since it reduces the formation of acrylamide, a carcinogenic compound. Since this enzyme is commonly used in two important industries, it is essential to enhance its half-life, reusability and catalytic activity. To date, to the best of our knowledge, a few studies have been reported to evaluate the catalytic efficiency of enzymes after exposure to magnetic fields. For instance, Mizuki et al. reported the activity of immobilized $\alpha$-amylase, lipase and chitinase activity increases in a rotational magnetic field and reaches maximum at a certain frequency. ${ }^{4}$ According to Prando et al. ${ }^{5}$ since the increase in activity due to magnetic treatment

${ }^{a}$ Department of Chemistry, Faculty of Science \& Arts, Inonu University, Malatya, 44280, Turkey. E-mail: burhan.ates@inonu.edu.tr; Fax: +90-422 341 0037; Tel: +904223773888

${ }^{b}$ Department of Physics, Faculty of Science \& Arts, Inonu University, Malatya, 44280, Turkey.E-mail: ahmet.ulu@inonu.edu.tr; Fax: +90-422 341 0037; Tel: +90-422 377 3774 may be related to an increase in the average particle size and a reduction of $25 \%$ in $\alpha$-helix content, the substrate facilitates access to the active site of lysozyme. Based on these results, the activities of some enzymes can be efficiently improved owing to exposure to magnetic field, which may make a great contribution to nanoscience and biotechnology.

In recent years, magnetic nanoparticles have received considerable interest and attention due to their versatile characteristics such as high surface area, superparamagnetism, stability, low toxicity, small and regular shape, inexpensiveness, and ease of synthesis. ${ }^{6,7}$ Therefore, they have been used for a broad range of applications including drug delivery, ${ }^{8}$ biosensors, ${ }^{9}$ catalysis, ${ }^{\mathbf{1 0}}$ and magnetic resonance imaging. ${ }^{11}$ Among them, enzyme immobilization is probably one of the most widely used applications. In particular, the separation of magnetic particles with an external magnet contributes to enhanced reusability of enzyme. However, magnetic nanoparticles tend to aggregate in aqueous medium due to the strong magnetic dipole-dipole attractions between particles. In addition, there are not many functional reactive groups, except a small amount of hydroxyl groups located on its surface, which will react with other molecules such as enzymes and proteins. ${ }^{\mathbf{1 2}}$ Perhaps, these drawbacks may hinder the applications of enzymes in industrial areas. ${ }^{\mathbf{1 3 , 1 4}}$ To overcome these drawbacks, modification of $\mathrm{Fe}_{3} \mathrm{O}_{4}$ nanoparticles is an efficient strategy using different molecules such as precious metals, ${ }^{15}$ carbon, ${ }^{\mathbf{1 6}}$ $\mathrm{SiO}_{2},{ }^{17} \mathrm{MCM}-41,{ }^{18}$ and polymers. ${ }^{19}$ At this point, biocompatible and biodegradable polymers are generally preferred because 

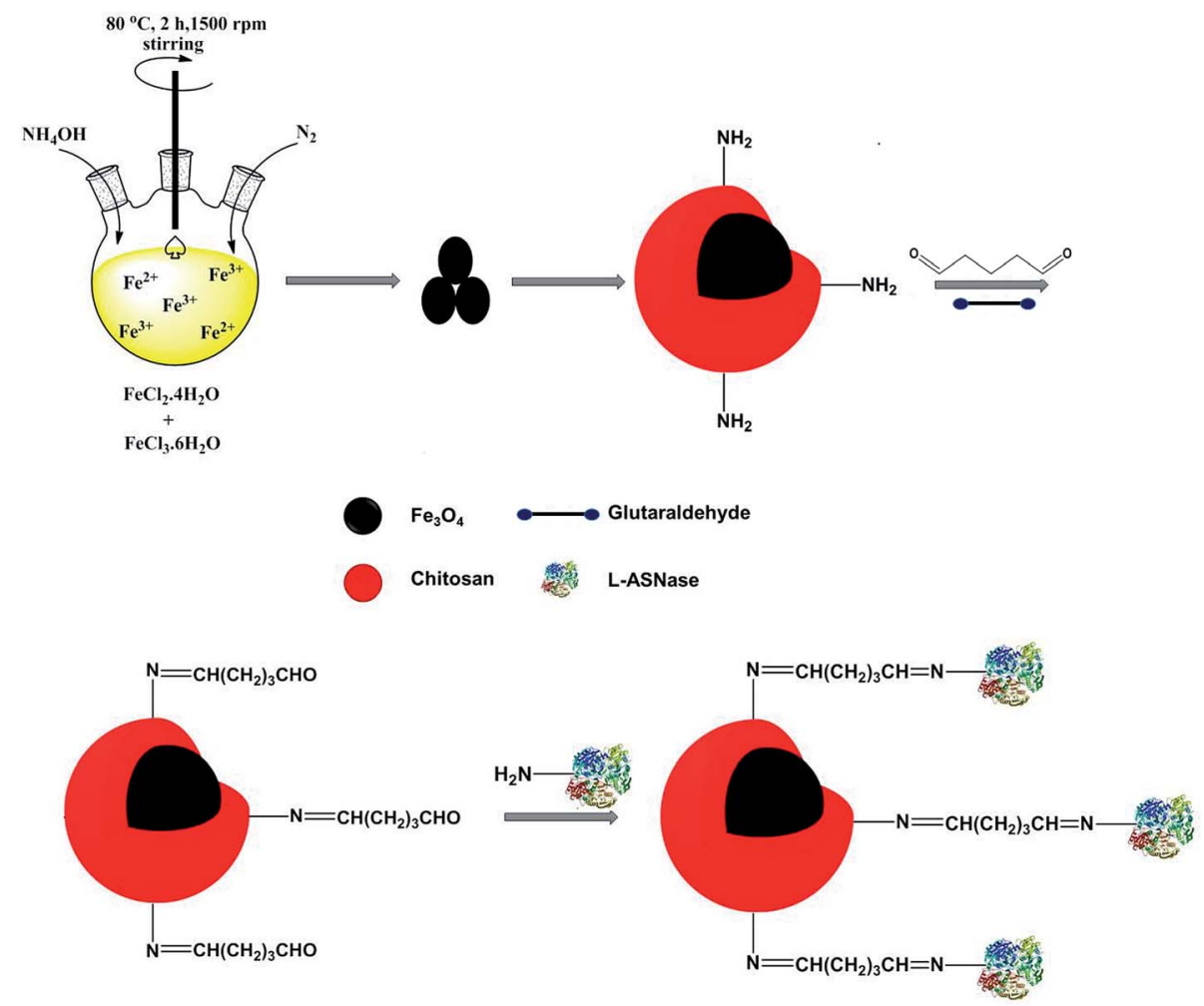

Fig. 1 Immobilization of L-ASNase onto the magnetic $\mathrm{Fe}_{3} \mathrm{O}_{4}$-chitosan core-shell particles.

they diminish unwanted toxicity of nanoparticles and offer active groups. ${ }^{14}$ Chitosan, a natural polymer derived from chitin, is found in the membrane of many organisms including lobsters, crabs, and shrimp. It is widely used as a biomaterial due to its features such as inexpensiveness, stability, biocompatibility, hydrophilicity, biodegradability, flexibility, versatility, and environment friendliness. ${ }^{20-22}$ Additionally, the amino groups in chitosan are very useful for the covalent attachment of enzyme onto the surface of chitosan. ${ }^{14}$ Therefore, chitosan can be considered as a promising support because of the aforementioned properties. Thus far, there are many reports about immobilization of enzyme on $\mathrm{Fe}_{3} \mathrm{O}_{4}$-chitosan particles. ${ }^{23-27}$

The main novelty of this study is that for the first time, we determined the effect of magnetic excitation caused by a weak magnetic field on the catalytic activity of the conjugated $\mathrm{L}^{-}$ ASNase. Therefore, L-ASNAse activity improved with magneticpropelled mechanism in a weak magnetic field, and may be used with improved efficiency in treatment of leukemia. In addition, for the first time, L-ASNase was immobilized on $\mathrm{Fe}_{3} \mathrm{O}_{4}$-chitosan particles via covalent attachment and the optimum parameters of the conjugated enzyme were investigated.

For this purpose, magnetic $\mathrm{Fe}_{3} \mathrm{O}_{4}$ nanoparticles were synthesized via co-precipitation technique. The $\mathrm{Fe}_{3} \mathrm{O}_{4}$ core was coated with chitosan to obtain core-shell structure magnetic nanoparticles. The thermal behavior, morphology and chemical composition of $\mathrm{Fe}_{3} \mathrm{O}_{4}$-chitosan magnetic nanoparticles were characterized by FTIR, TGA, DTA, DSC, SEM and EDX analysis. In addition, the hydrodynamic particle size, surface charge, structure and magnetic property of $\mathrm{Fe}_{3} \mathrm{O}_{4}$-chitosan nanoparticles were characterized by DLS, Zetasizer Nano ZS, XRD and VSM, respectively. L-ASNase was covalently immobilized onto the $\mathrm{Fe}_{3} \mathrm{O}_{4}$-chitosan magnetic particles using glutaraldehyde as an activating reagent (Fig. 1). The characterization of conjugated L-ASNase was performed through several technics including FTIR, SEM and XRD. In addition, the optimum $\mathrm{pH}$ and temperature, $\mathrm{pH}$ and thermal stability, kinetic parameters, reusability and storage capability of the conjugated enzyme were investigated and were compared with those of free enzyme. Moreover, we examined and discussed the activity of conjugated L-ASNase exposed to an external weak magnetic field using different frequency or flux density.

\section{Experimental}

\subsection{Materials}

Iron(II) chloride tetrahydrate $\left(\mathrm{FeCl}_{2} \cdot 4 \mathrm{H}_{2} \mathrm{O}\right)$ and iron(III) chloride hexahydrate $\left(\mathrm{FeCl}_{3} \cdot 6 \mathrm{H}_{2} \mathrm{O}\right)$ were purchased from Merck (Darmstadt, Germany). L-Asn, chitosan (medium molecular weight, deacetylation: 75-85\%), acetic acid, glutaraldehyde (GDA, 25\%, $\mathrm{v} / \mathrm{v}$ ), sodium hydroxide $(\mathrm{NaOH})$, and ammonium hydroxide $\left(\mathrm{NH}_{4} \mathrm{OH}, 26 \mathrm{wt} \%\right)$ were supplied by Sigma-Aldrich (St. Louis, MO). L-ASNase from Escherichia coli was purchased from ProSpec-Tany TechnoGene Ltd. Trichloroacetic acid (TCA) was obtained from Riedel de Haen (Deelze, Germany). Unless otherwise noted, all reagents and chemicals were of analytical or biological grade. Ultra-pure water (Milli Q, Millipore) was used to prepare all aqueous solutions used in this study. 


\subsection{Preparation of $\mathrm{Fe}_{3} \mathrm{O}_{4}$ and $\mathrm{Fe}_{3} \mathrm{O}_{4}$-chitosan carriers}

Magnetic $\mathrm{Fe}_{3} \mathrm{O}_{4}$ nanoparticles were synthesized by a coprecipitation method using ferric and ferrous salts. ${ }^{24} \mathrm{FeCl}_{2}$ $\cdot 4 \mathrm{H}_{2} \mathrm{O}(1.99 \mathrm{~g})$ and $\mathrm{FeCl}_{3} \cdot 6 \mathrm{H}_{2} \mathrm{O}(5.4 \mathrm{~g})$ were dissolved in $50 \mathrm{~mL}$ of deionized water. The $\mathrm{pH}$ of this mixture was adjusted by adding ammonia solution ( $26 \mathrm{wt} \%$ ). The reaction was allowed to continue for $2 \mathrm{~h}$ at $80^{\circ} \mathrm{C}$ under the protection of nitrogen. The obtained $\mathrm{Fe}_{3} \mathrm{O}_{4}$ nanoparticles were separated by using an external magnet and washed with distilled water to remove excess ammonia. Finally, the precipitate was dried at $60{ }^{\circ} \mathrm{C}$ for $6 \mathrm{~h}$. In order to prepare $\mathrm{Fe}_{3} \mathrm{O}_{4}$-chitosan carrier, chitosan $(0.3 \mathrm{~g})$ was completely dissolved in $2 \%(\mathrm{v} / \mathrm{v})$ acetic acid solution. Then, dry $\mathrm{Fe}_{3} \mathrm{O}_{4}$ nanoparticles $(0.15 \mathrm{~g})$ were added to chitosan solution. The solution was dispersed homogeneously by ultrasonication for $20 \mathrm{~min}$. Subsequently, $50 \mathrm{~mL}$ of $1 \mathrm{M} \mathrm{NaOH}$ solution was added to the mixture and the $\mathrm{Fe}_{3} \mathrm{O}_{4}$-chitosan particles were obtained. The obtained particles were washed with deionized water until neutral $\mathrm{pH}$ was obtained. Finally, the particles were dried again in the vacuum oven at $50{ }^{\circ} \mathrm{C}$ for $12 \mathrm{~h}$ and stored at $4{ }^{\circ} \mathrm{C}$ for immobilization.

\subsection{Characterization of magnetic $\mathrm{Fe}_{3} \mathrm{O}_{4}$-chitosan carriers}

The structural characterization of magnetic $\mathrm{Fe}_{3} \mathrm{O}_{4}$-chitosan particles was performed by FTIR spectroscopy (Perkin Elmer). Thermogravimetric analysis (TGA) and differential thermal analysis (DTA) studies were performed using a Shimadzu Thermal Analyzer at room temperature to $700{ }^{\circ} \mathrm{C}$ a rate of $10{ }^{\circ} \mathrm{C} \min ^{-1}$ in air atmosphere. Differential Scanning Calorimetry (DSC) was performed on a Shimadzu DSC-60 at a heating rate of $20{ }^{\circ} \mathrm{C} \mathrm{min}^{-1}$ from 0 to $450{ }^{\circ} \mathrm{C}$. Crystalline phases of the samples were verified using powder X-ray diffraction (XRD, Rigaku RadB X-ray diffractometer). Morphology of the assynthesized nanomaterial was determined using by scanning electron microscope (SEM, LEO Evo-40 VPX). Magnetization of the as-prepared nanoparticles was measured on a VSM (PPMS) at room temperature. EDX analysis was performed using a Ronteck Xflash detector analyzer equipped with Leo-Evo 40xVP. The average hydrodynamic particle size was measured using dynamic light scattering (DLS). Zeta potential

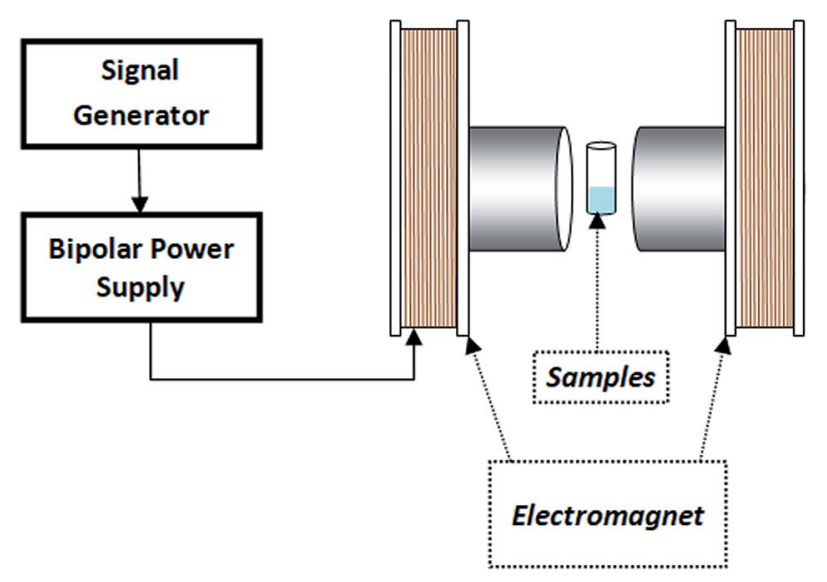

Fig. 2 Schematic of magnetic field experiments(VSM). measurements were performed using Malvern Zetasizer Nano ZS. L-ASNase activity was observed by an ELISA plate reader (BioTek) at $480 \mathrm{~nm}$.

\subsection{Immobilization of $\mathrm{L}$-ASNase onto $\mathrm{Fe}_{3} \mathrm{O}_{4}$-chitosan carriers}

L-ASNase was covalently immobilized onto $\mathrm{Fe}_{3} \mathrm{O}_{4}$-chitosan carriers by the following procedure. First, $1.0 \mathrm{~g}$ support was reacted with $30 \mathrm{~mL}$ of $2.5 \%(\mathrm{v} / \mathrm{v})$ GDA solution with stirring at $25{ }^{\circ} \mathrm{C}$ for $2 \mathrm{~h}$ to activate the support by offering aldehyde groups. ${ }^{24}$ Then, the modified support was rinsed with deionized water three times to remove excess unreacted GDA. L-ASNase was dissolved in Tris-HCl buffer and mixed with an appropriate amount of $\mathrm{Fe}_{3} \mathrm{O}_{4}$-chitosan particles. The mixture was shaken in Eppendorf tube for immobilization by chemical bonding at $4{ }^{\circ} \mathrm{C}$ for $24 \mathrm{~h}$. Subsequently, the particles were collected by an external magnet and then washed with 2 times Tris-HCl buffer to remove unconjugated L-ASNase. The solid particles were dried at room temperature and stored in the refrigerator at $4{ }^{\circ} \mathrm{C}$ until further use. In addition, the supernatant and washing solutions were stored at $4{ }^{\circ} \mathrm{C}$ to calculate immobilization

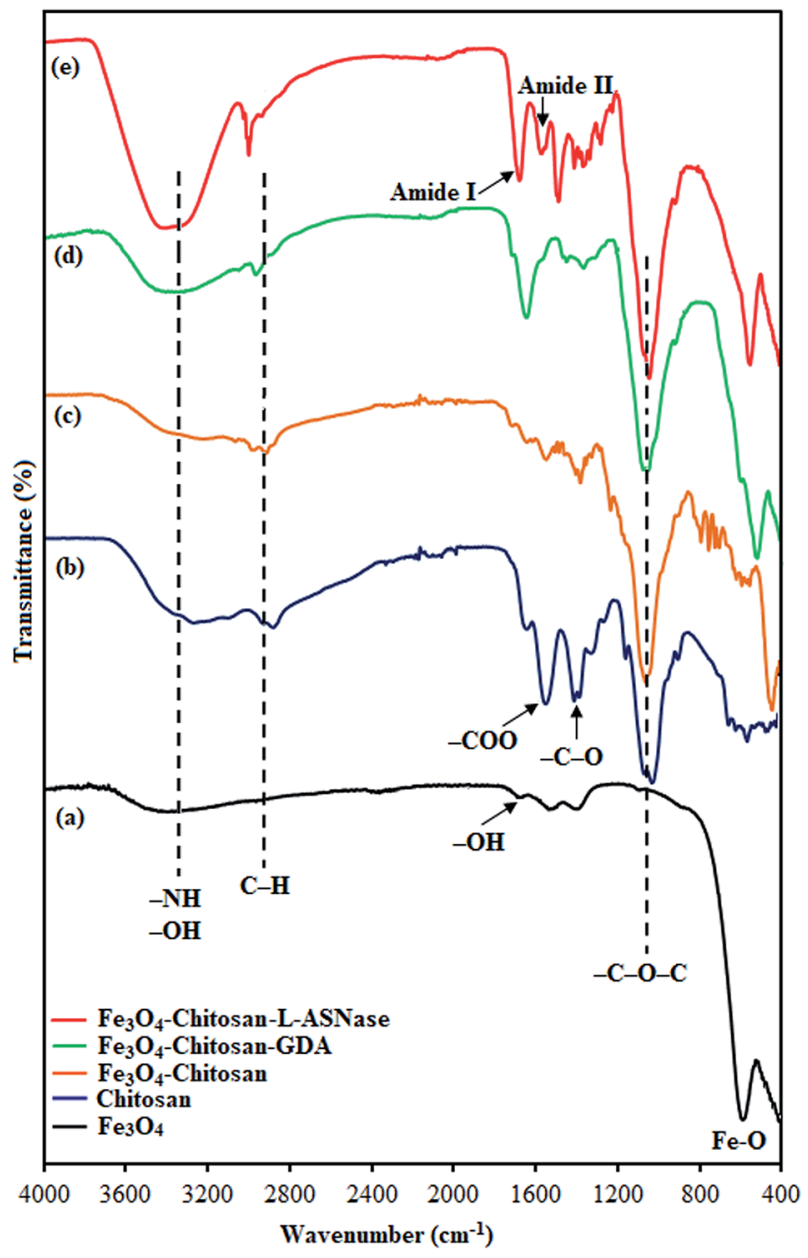

Fig. 3 FTIR spectra of (a) $\mathrm{Fe}_{3} \mathrm{O}_{4}$, (b) chitosan, (c) $\mathrm{Fe}_{3} \mathrm{O}_{4}$-chitosan particles, (d) $\mathrm{Fe}_{3} \mathrm{O}_{4}$-chitosan-GDA, and (e) $\mathrm{Fe}_{3} \mathrm{O}_{4}$-chitosan-LASNase. 
efficiency (IE). The protein concentration of the reaction mixture was measured by the Bradford method using bovine serum albumin (BSA) as standard. ${ }^{28}$ The following formula was used to determine immobilization efficiency:

$$
\mathrm{IE}=\left[\frac{\left(A_{0}-B_{1}-B_{2}\right)}{A_{0}}\right] \times 100
$$

where $A_{0}$ is the total protein content of the free enzyme preparation and $B_{1}$ and $B_{2}$ are the protein content of supernatant and wash solution after immobilization, respectively.

\subsection{Assay of L-ASNase activity}

The assay of free and conjugated enzyme activity was determined by the Nesslerization method, as previously reported. ${ }^{29}$ The method is based on colorimetric measurement of the amount of ammonia released during the hydrolysis of L-Asn. The reaction mixture contains $1.0 \mathrm{~mL}$ of $0.01 \mathrm{M} \mathrm{L}$-Asn (prepared in $0.05 \mathrm{M}$ Tris- $\mathrm{HCl}$ buffer at $\mathrm{pH} 8.6)$ and free $(20 \mu \mathrm{L})$ or conjugated enzyme ( $5 \mathrm{mg}$ ). The mixture was incubated at $37{ }^{\circ} \mathrm{C}$ for 15 minutes. The enzymatic reaction was terminated by adding $0.1 \mathrm{~mL}$ of $1.5 \mathrm{M}$ TCA. The conjugated enzyme was removed by centrifugation at $5000 \mathrm{rpm}$ for $5 \mathrm{~min}$. The supernatant $(100 \mu \mathrm{L})$ was added into the well containing Nessler's reagent $(100 \mu \mathrm{L})$. The well-plate was incubated at room temperature for $10 \mathrm{~min}$. The observed yellow color was read using an ELISA microplate reader (Biotek, EON) at $480 \mathrm{~nm}$. One unit (U) of L-ASNase is defined as the amount of enzyme that catalyzed the formation of $1 \mu \mathrm{mol}$ of ammonia from $\mathrm{L}$-Asn per minute under the standard assay conditions. ${ }^{30}$ All the experiments were repeated three or more times. The highest L-ASNase activity was considered $100 \%$ while calculating the relative activities.

\subsection{Characterization of the conjugated L-ASNase}

2.6.1 Effect of $\mathbf{p H}$ and temperature. The effect of $\mathrm{pH}$ on the activities of free and conjugated L-ASNase was investigated by performing the enzyme assay in the $\mathrm{pH}$ range of $4-10$ at $37^{\circ} \mathrm{C}$. The buffers used were citrate (0.05 M, pH 4-6), phosphate (0.05 M, pH 7-8), and Tris-HCl (0.05 M, pH, 8.5-10).

The influence of the temperature on the activities of free and conjugated $\mathrm{L}$-ASNase was studied from 25 to $70{ }^{\circ} \mathrm{C}$ with interval of $5{ }^{\circ} \mathrm{C}$ at $\mathrm{pH} 8.0$ and 8.5.

2.6.2 $\mathrm{pH}$ and thermal stability. In order to evaluate the $\mathrm{pH}$ stability of the free and conjugated L-ASNase, the relevant enzymes were incubated at acidic ( $\mathrm{pH}: 5.0)$ and alkaline (pH: 9.0) $\mathrm{pH}$ values, and the activity measurements were performed for $180 \mathrm{~min}$. After every $30 \mathrm{~min}$, the residual activity of free and conjugated L-ASNase was measured. The relative activity was calculated from the ratio of residual activity to the initial activity of each sample.

For thermal stability experiments, free and conjugated enzymes were incubated in a water bath at $55{ }^{\circ} \mathrm{C}$ for different durations ranging from 30 to $180 \mathrm{~min}$. After incubation, the residual activities were determined using the abovementioned assay.

2.6.3 Kinetic experiments. The kinetic parameters $\left(K_{\mathrm{m}}\right.$ and $\left.V_{\max }\right)$ of the free and conjugated L-ASNase were calculated from the Lineweaver-Burk plot at the substrate concentrations ranging from 0.01 to $50 \mathrm{mM}$.

2.6.4 Reusability and storage stability. To investigate the reusability, the conjugated L-ASNase was reused 16 times at optimal assay conditions. After each activity assay, the support was removed from the reaction system by using an external magnet and washed thoroughly with deionized water. Then, fresh substrate solution was added to the conjugated enzyme and the residual activity was calculated according to the standard L-ASNase assay.

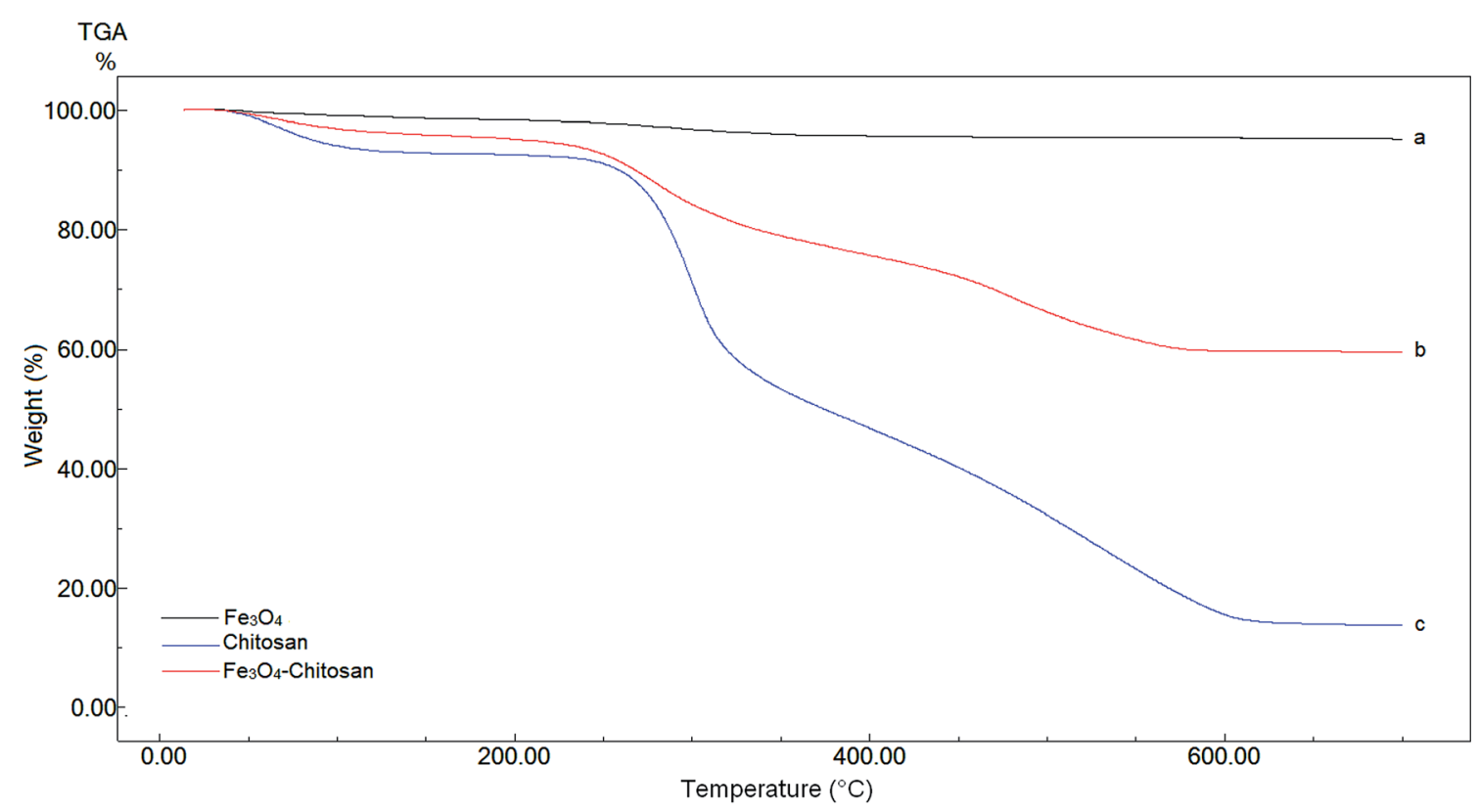

Fig. 4 TGA curves of (a) $\mathrm{Fe}_{3} \mathrm{O}_{4}$, (b) chitosan, and (c) $\mathrm{Fe}_{3} \mathrm{O}_{4}$-chitosan particles. 


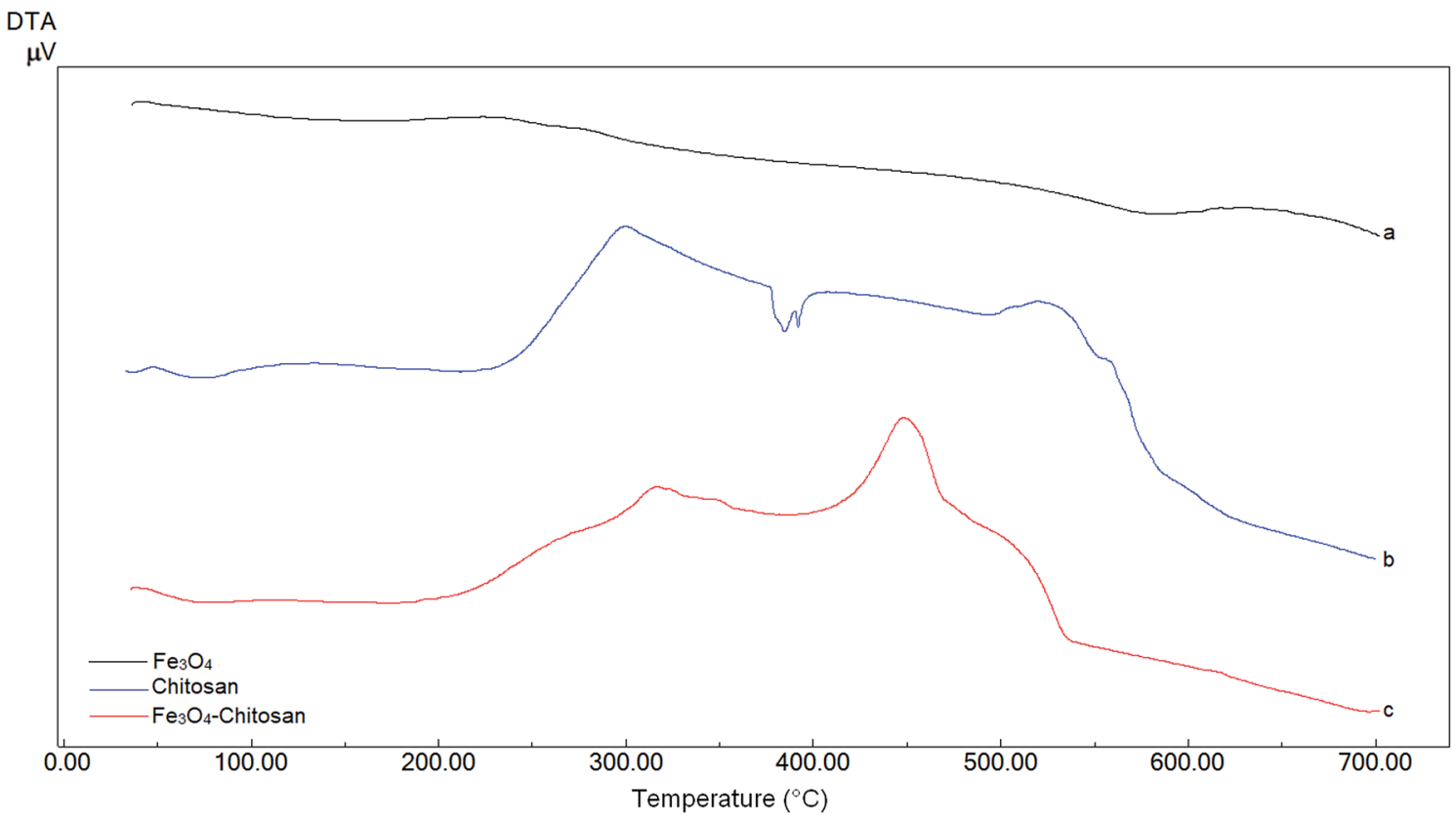

Fig. 5 DTA curves of (a) $\mathrm{Fe}_{3} \mathrm{O}_{4}$, (b) chitosan, and (c) $\mathrm{Fe}_{3} \mathrm{O}_{4}$-chitosan particles.

Storage stability was measured by determining the activity of free and conjugated L-ASNase every two days for a period of 30 days at $4{ }^{\circ} \mathrm{C}$ and $25{ }^{\circ} \mathrm{C}$. The activity at the first day was taken to be $100 \%$.

2.6.5 Magnetic-propelled experiments. To determine the effect of magnetic field on enzyme activity, the system shown in Fig. 2 was designed and used. The as-synthesized magnetic $\mathrm{Fe}_{3} \mathrm{O}_{4}$-chitosan-L-ASNase particles $(5 \mathrm{mg})$ were transferred to test tubes. The test tubes were placed at the center of the magnetic field at $1,3,5,10$ and $30 \mathrm{~Hz}$, respectively. The flux density of the magnetic field was set at $10 \mathrm{mT}$. Then, $1000 \mu \mathrm{L}$ of substrate solution was immediately added and the enzymatic reaction was started at $25{ }^{\circ} \mathrm{C}$ for 10 minutes. The reaction was terminated by adding $100 \mu \mathrm{L}$ of $1.5 \mathrm{M}$ TCA, and activity measurements were assayed according to the description in the section "Assay of L-ASNase". Control assays were performed keeping the free enzyme at same conditions in absence of magnetic field.

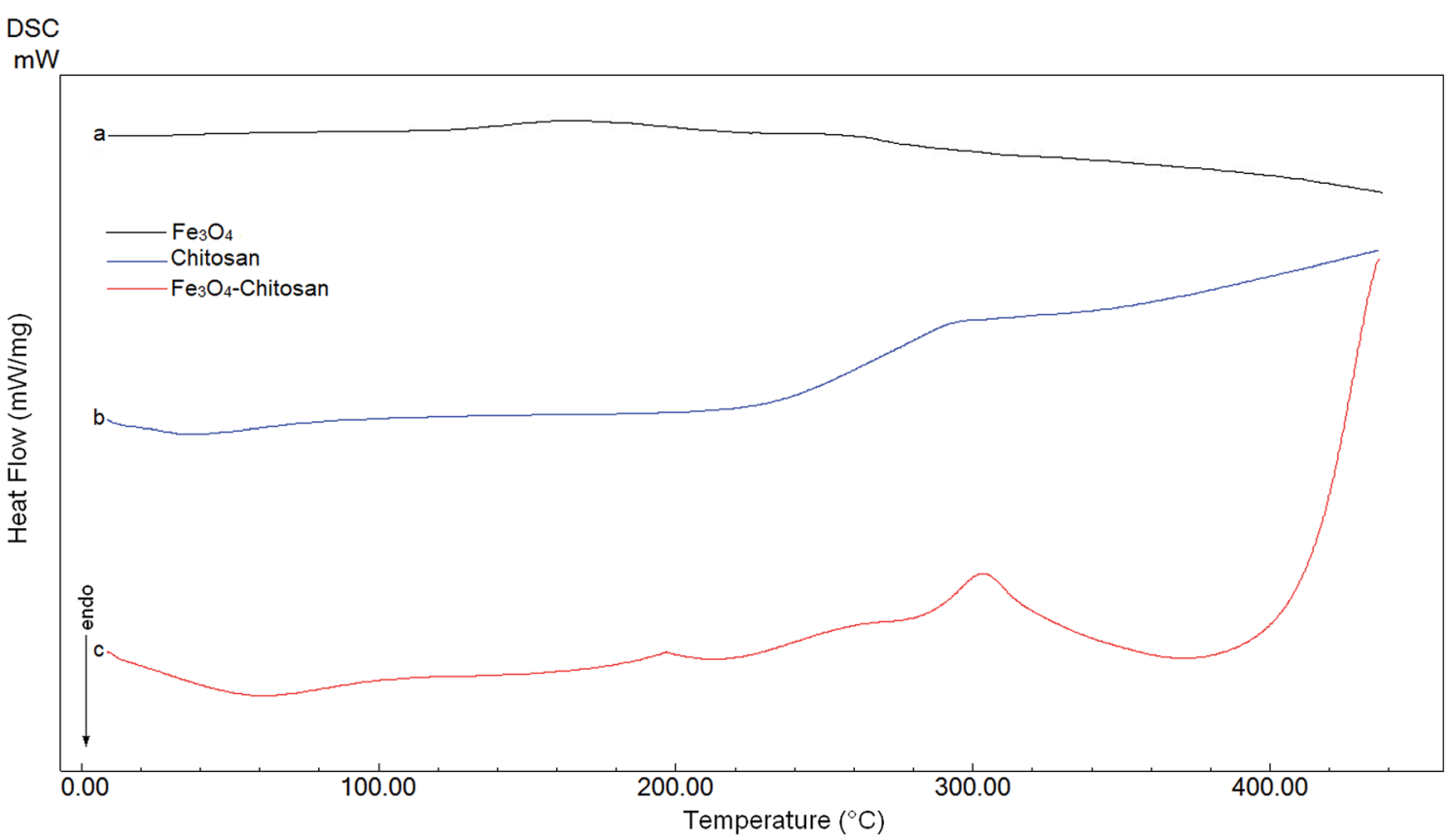

Fig. 6 DSC curves of (a) $\mathrm{Fe}_{3} \mathrm{O}_{4}$, (b) chitosan, and (c) $\mathrm{Fe}_{3} \mathrm{O}_{4}$-chitosan particles. 


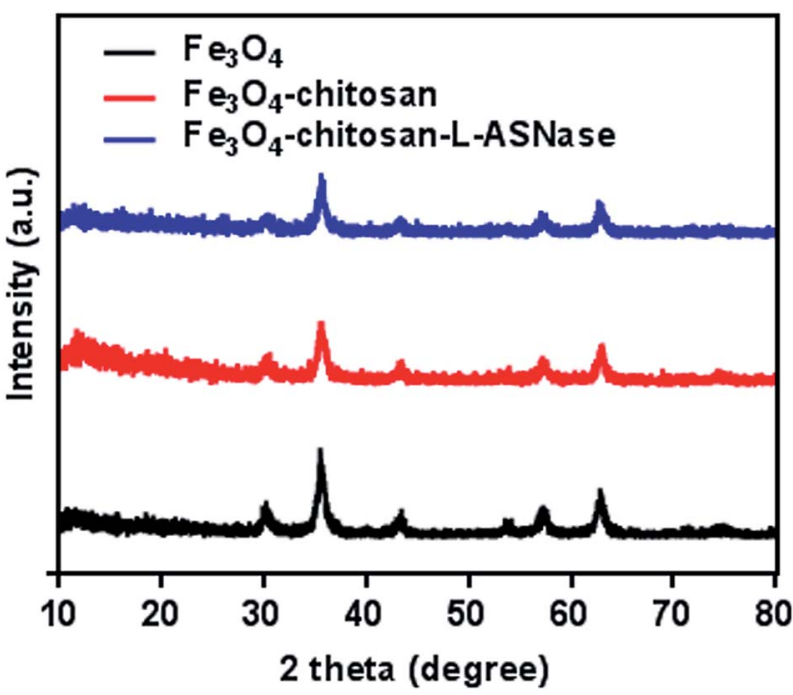

Fig. 7 XRD patterns of the $\mathrm{Fe}_{3} \mathrm{O}_{4}, \mathrm{Fe}_{3} \mathrm{O}_{4}$-chitosan particles, and $\mathrm{Fe}_{3} \mathrm{O}_{4}$-chitosan-L-ASNase.

In addition, the influence of magnetic flux density on enzyme activity was examined at different flux densities $(10,20$, $30,40,50$ and $100 \mathrm{mT}$ ) with constant frequency $(3 \mathrm{~Hz})$. For this experiment, we repeated the above enzyme assay.

\section{Result and discussion}

\subsection{Characterization of magnetic $\mathrm{Fe}_{3} \mathrm{O}_{4}$-chitosan carriers}

In order to characterize the functional groups on the surface of the samples, FTIR analyses were performed, as shown in Fig. 3. The characteristic peak of pristine $\mathrm{Fe}_{3} \mathrm{O}_{4}$, ascribed to the stretching vibration of $\mathrm{Fe}-\mathrm{O}$ bonds, appeared at $560 \mathrm{~cm}^{-1}$ (Fig. 3a). ${ }^{31}$ The other peaks at around $3400 \mathrm{~cm}^{-1}$ and $1630 \mathrm{~cm}^{-1}$ correspond to the adsorbed water in the sample..$^{32}$ For chitosan (Fig. 3b), the FTIR spectra shows bands arising from stretching of -NH and -OH groups $\left(3400 \mathrm{~cm}^{-1}\right), \mathrm{C}-\mathrm{H}\left(2871\right.$ and $\left.2929 \mathrm{~cm}^{-1}\right)$ stretching vibrations, and from amide II bending $\left(1569 \mathrm{~cm}^{-1}\right){ }^{33}$ In addition, the bands at 1060, 1368 and $1400 \mathrm{~cm}^{-1}$ were assigned to the stretching vibrations of $-\mathrm{C}-\mathrm{O}-\mathrm{C},-\mathrm{C}-\mathrm{O}$ and -COO groups, respectively. ${ }^{34-36}$ As expected, the FTIR spectrum of $\mathrm{Fe}_{3} \mathrm{O}_{4}$-chitosan showed characteristic bands of both $\mathrm{Fe}_{3} \mathrm{O}_{4}$ and chitosan. However, in the spectrum of $\mathrm{Fe}_{3} \mathrm{O}_{4}$-chitosan particles (Fig. 3c), the peak of $\mathrm{Fe}-\mathrm{O}$ vibration at $560 \mathrm{~cm}^{-1}$ shifted to $440 \mathrm{~cm}^{-1}$ due to the interaction between $\mathrm{Fe}_{3} \mathrm{O}_{4}$ and chitosan compared with that observed in the spectrum of pristine $\mathrm{Fe}_{3} \mathrm{O}_{4} \cdot{ }^{37,38}$ These results indicated that the $\mathrm{Fe}_{3} \mathrm{O}_{4}$ magnetic nanoparticles were coated by the chitosan. For $\mathrm{Fe}_{3} \mathrm{O}_{4}-$ chitosan-GDA, the new absorption peaks at $1645 \mathrm{~cm}^{-1}(\mathrm{C}=\mathrm{N}$, imine bond) and $1587 \mathrm{~cm}^{-1}(\mathrm{C}=\mathrm{C}$ bond) confirmed that crosslinking occurred between chitosan and GDA (Fig. 3d). Similar absorption peaks were observed in some reports of chitosan cross-linked with GDA. ${ }^{39,40}$ The FTIR spectrum of $\mathrm{Fe}_{3} \mathrm{O}_{4}$-chitosan-L-ASNase is presented in Fig. 3e. In this spectrum, intense $\mathrm{OH}$ stretching band in the range of $3400-3600 \mathrm{~cm}^{-1}$ is attributed to the presence of enzyme. ${ }^{41}$ In addition, the increase in the intensity of two peaks at $1654 \mathrm{~cm}^{-1}$ (amide I bending) and $1553 \mathrm{~cm}^{-1}$ (amide II bending) is further evidence of the successful immobilization of L-ASNase. ${ }^{42}$

TGA analysis of pure $\mathrm{Fe}_{3} \mathrm{O}_{4}$, chitosan and magnetic $\mathrm{Fe}_{3} \mathrm{O}_{4^{-}}$ chitosan carriers were performed between $0{ }^{\circ} \mathrm{C}$ and $700{ }^{\circ} \mathrm{C}$ for quantitative analysis. These thermograms are given in Fig. 4. In the thermogram of pure $\mathrm{Fe}_{3} \mathrm{O}_{4}$, weight loss is not observed up to $700{ }^{\circ} \mathrm{C}$. Three weight losses are observed in the TGA thermogram of pure chitosan. The first thermal degradation of chitosan structure resulted from the loss of moisture from 60 to $110{ }^{\circ} \mathrm{C}$. The second thermal decomposition was observed between 220 and $310{ }^{\circ} \mathrm{C}$ due to the decomposition of polymer with low molecular weight. The third thermal decomposition presented $40 \%$ weight loss between $310{ }^{\circ} \mathrm{C}$ and $590{ }^{\circ} \mathrm{C}$. This weight loss stems from the decomposition of cyclic moiety (saccharide rings). The magnetic $\mathrm{Fe}_{3} \mathrm{O}_{4}$-chitosan particles show a similar thermal decomposition profile to that of chitosan i.e., there are three different weight losses in the TGA thermogram of the magnetic $\mathrm{Fe}_{3} \mathrm{O}_{4}$-chitosan carriers. These weight losses are due to the loss of physiosorbed water between $50-110{ }^{\circ} \mathrm{C}$, the degradation of the chitosan polymeric structure between $200{ }^{\circ} \mathrm{C}$ and $320^{\circ} \mathrm{C}$ and the saccharide ring breaking peak $320^{\circ} \mathrm{C}$ and $550{ }^{\circ} \mathrm{C}$. However, the weight loss of $\mathrm{Fe}_{3} \mathrm{O}_{4}$-chitosan is very different from that of chitosan. $\mathrm{Fe}_{3} \mathrm{O}_{4}$ and chitosan were connected together through the chelation between $\mathrm{Fe}^{3+}$ and chitosan in the course of the reaction. The conformational changes of chitosan and the additional bridging between $\mathrm{Fe}_{3} \mathrm{O}_{4}$ and chitosan enhanced the thermal stability of chitosan in $\mathrm{Fe}_{3} \mathrm{O}_{4}-$ chitosan. Therefore, the final decomposition temperature of $\mathrm{Fe}_{3} \mathrm{O}_{4}$-chitosan was higher than that for pure chitosan. Similar
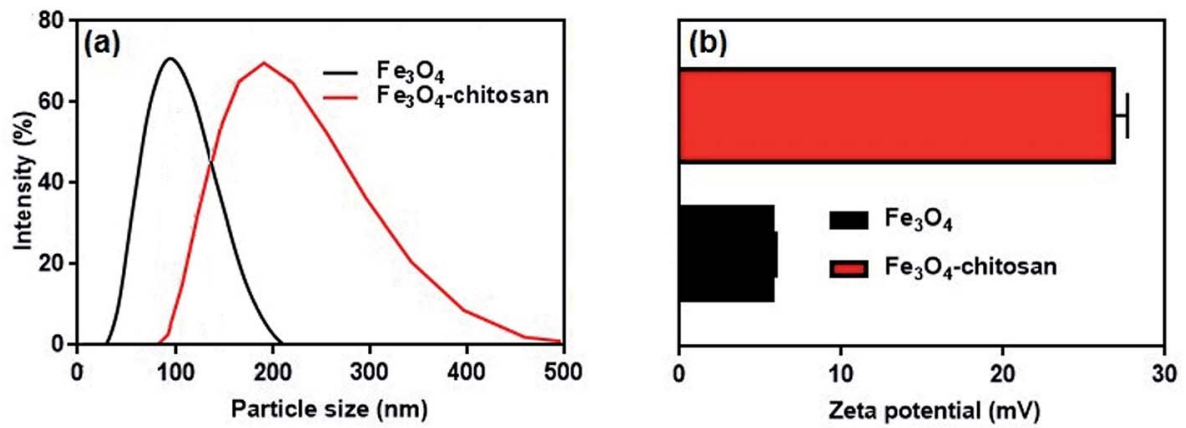

Fig. 8 (a) Hydrodynamic particle size distribution and (b) zeta potential values of $\mathrm{Fe}_{3} \mathrm{O}_{4}$ nanoparticles and $\mathrm{Fe}_{3} \mathrm{O}_{4}-\mathrm{chitosan}$ particles. 

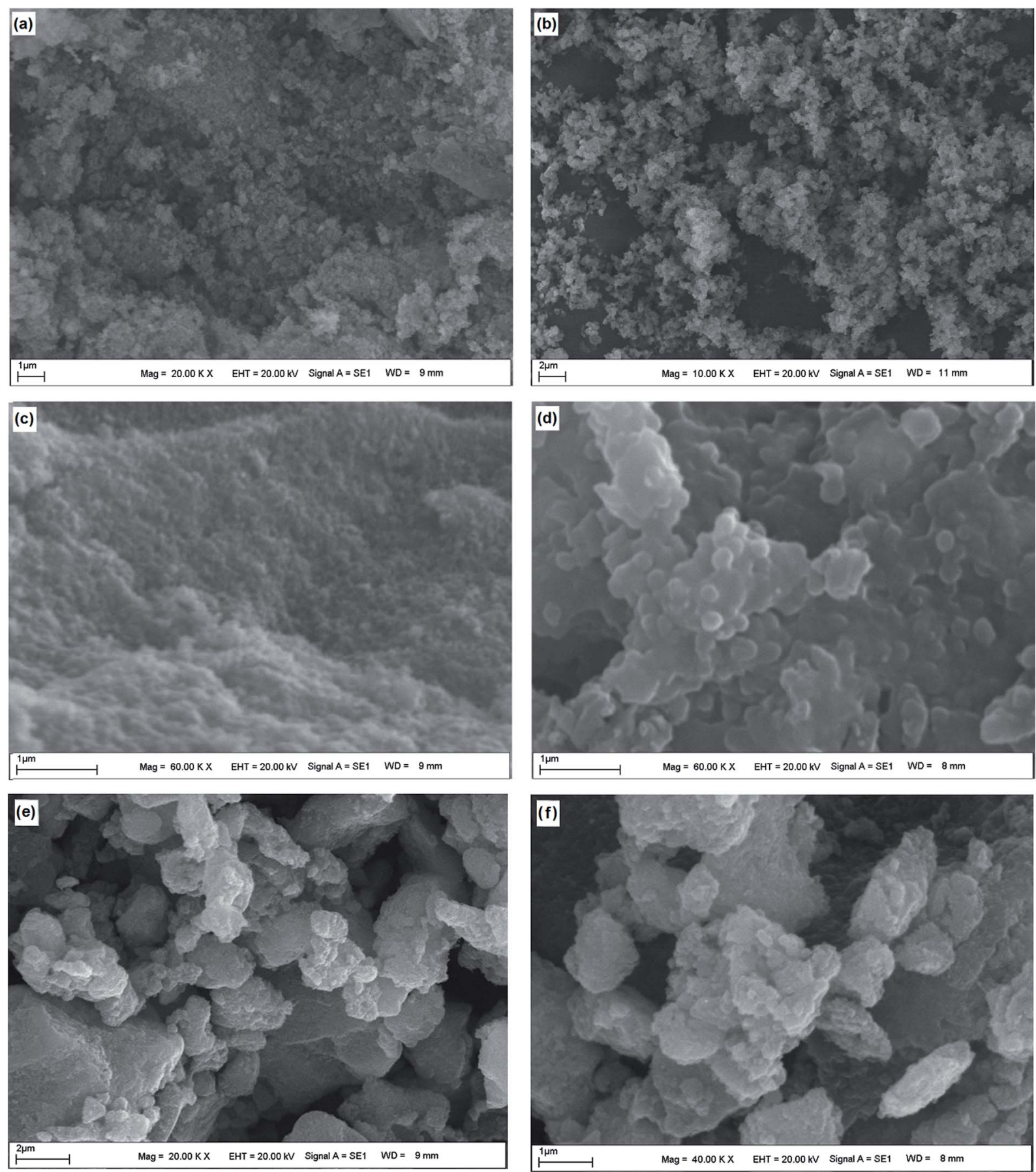

Fig. 9 SEM analysis of magnetic (a and c) $\mathrm{Fe}_{3} \mathrm{O}_{4}$, ( $b$ and d) $\mathrm{Fe}_{3} \mathrm{O}_{4}-$ chitosan particles and (e and f) $\mathrm{Fe}_{3} \mathrm{O}_{4}-$ chitosan-L-ASNase at different magnifications.

TGA thermograms have also been reported previously. ${ }^{\mathbf{4 3 4 4}}$ The TGA thermogram results of $\mathrm{Fe}_{3} \mathrm{O}_{4}$-chitosan structure indicate that $\mathrm{Fe}_{3} \mathrm{O}_{4}$ nanoparticles are successfully functionalized with chitosan groups. In addition, these thermal analysis results were confirmed by DTA and DSC techniques.

DTA thermograms of $\mathrm{Fe}_{3} \mathrm{O}_{4}$, chitosan and magnetic $\mathrm{Fe}_{3} \mathrm{O}_{4}-$ chitosan carriers are shown in Fig. 5; the thermogram of the magnetic $\mathrm{Fe}_{3} \mathrm{O}_{4}$-chitosan carriers shows three exothermic peaks. The first exothermic peak at about $100{ }^{\circ} \mathrm{C}$ is due to loss of water and second peak at about $320{ }^{\circ} \mathrm{C}$ is related to the decomposition of polymeric structure of chitosan structure. The last exothermic peak at about $400{ }^{\circ} \mathrm{C}$ is due to the degradation of saccharide ring groups. Moreover, DSC thermograms of the $\mathrm{Fe}_{3} \mathrm{O}_{4}$, chitosan and magnetic $\mathrm{Fe}_{3} \mathrm{O}_{4}$-chitosan carriers are shown in Fig. 6. No significant peaks were detected in the DSC thermogram of $\mathrm{Fe}_{3} \mathrm{O}_{4}$ nanoparticles. However, the $T_{\mathrm{g}}$ was observed at $30{ }^{\circ} \mathrm{C}$ in the DSC thermogram of chitosan. ${ }^{45}$ In addition, this DSC thermogram shows that the decomposition 

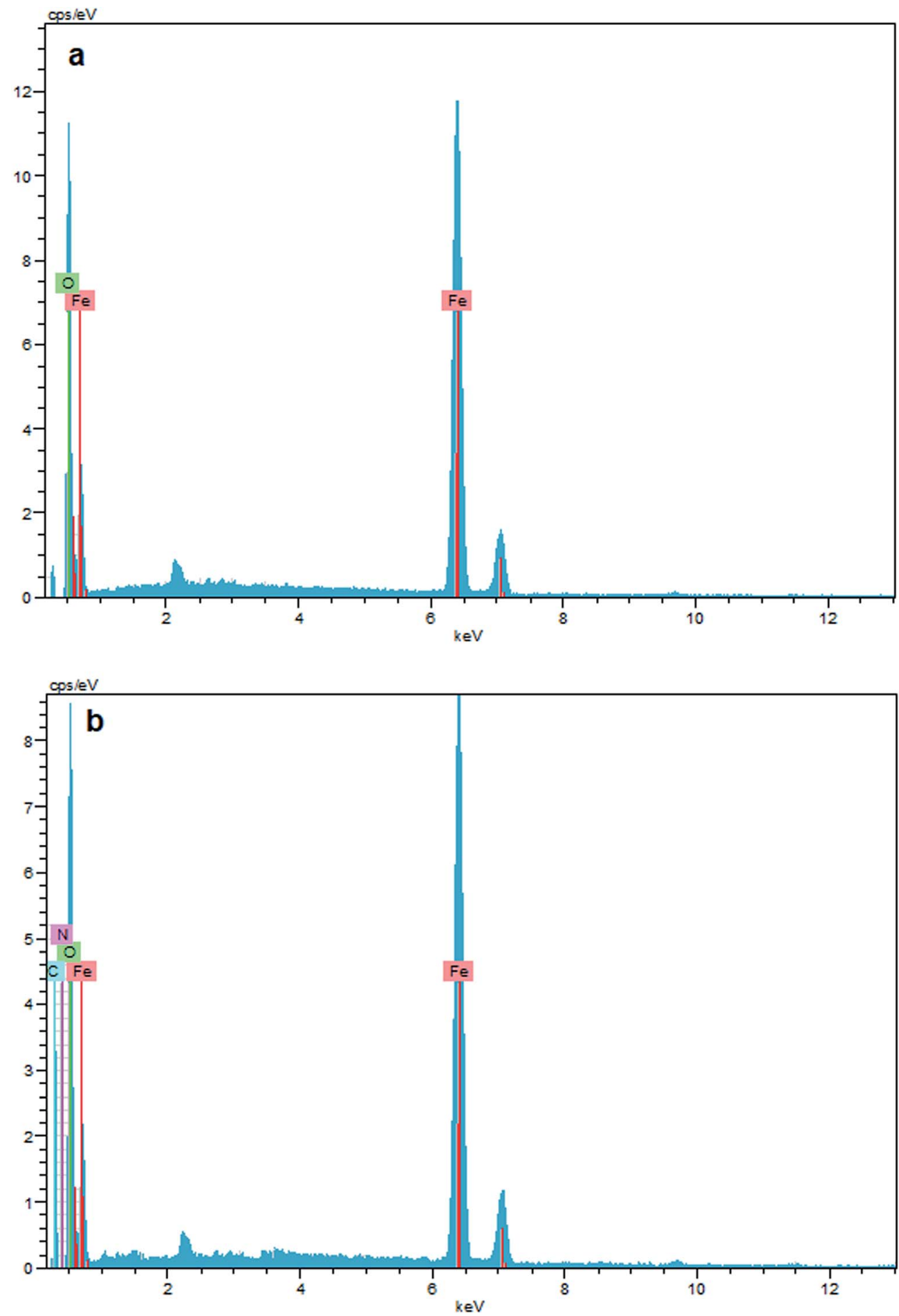

Fig. 10 EDX result of (a) $\mathrm{Fe}_{3} \mathrm{O}_{4}$, and (b) $\mathrm{Fe}_{3} \mathrm{O}_{4}$-chitosan particles.

of chitosan started at $220{ }^{\circ} \mathrm{C} .{ }^{46,47}$ In the DSC thermogram of $\mathrm{Fe}_{3} \mathrm{O}_{4}$-chitosan, the exothermic peaks between $220{ }^{\circ} \mathrm{C}$ and $380{ }^{\circ} \mathrm{C}$ corresponds to the oxidative decomposition of organic group onto the $\mathrm{Fe}_{3} \mathrm{O}_{4}$ nanoparticle surface.

To verify the presence of crystalline $\mathrm{Fe}_{3} \mathrm{O}_{4}$ and $\mathrm{Fe}_{3} \mathrm{O}_{4}$-chitosan particles, the structure of the magnetic nanoparticles was characterized by XRD and the diffractogram is shown in Fig. 7. In both samples, six characteristic peaks were observed ((220),
(311), (400), (422), (511), and (440)). ${ }^{48}$ These peaks are consistent with the database in JCPDS file (PDF No. 65-3107) and reveal that the resultant nanoparticles are pure $\mathrm{Fe}_{3} \mathrm{O}_{4}$ with a spinel structure. ${ }^{25}$ The weaker diffraction lines of magnetic $\mathrm{Fe}_{3} \mathrm{O}_{4}-$ chitosan particles confirm that the $\mathrm{Fe}_{3} \mathrm{O}_{4}$ nanoparticles were coated by amorphous chitosan polymer. ${ }^{49}$ In addition, chitosan did not result in phase change of $\mathrm{Fe}_{3} \mathrm{O}_{4}$ nanoparticles. The conjugation of L-ASNase leads to a decrease in the intensity of 
all the characteristic peaks, which may be due to the interaction of the $\mathrm{Fe}_{3} \mathrm{O}_{4}$-chitosan particles with enzyme. XRD measurements further confirmed the abovementioned FTIR results.

The average hydrodynamic particle sizes of $\mathrm{Fe}_{3} \mathrm{O}_{4}$ and $\mathrm{Fe}_{3} \mathrm{O}_{4}-$ chitosan are $100 \mathrm{~nm}$ and $>200 \mathrm{~nm}$, respectively (Fig. 8a). The increase in the hydrodynamic size of functionalized $\mathrm{Fe}_{3} \mathrm{O}_{4}$ nanoparticles is due to the interaction between amino groups of chitosan with hydroxyl groups onto the surface of the $\mathrm{Fe}_{3} \mathrm{O}_{4}$. It has also been reported in previous studies that the particle size increases after nanoparticles are coated with chitosan. ${ }^{35,36,50}$

It is well known that zeta potential measurements might provide some additional insights into the magnitude of the repulsion or attraction between particles. ${ }^{51}$ Therefore, the successful coating of chitosan was confirmed by the zeta potential analysis of the resulting composite. The zeta potential results are shown in Fig. $8 \mathrm{~b}$. The zeta potential of unmodified magnetic $\mathrm{Fe}_{3} \mathrm{O}_{4}$ is $5.74 \pm 0.22 \mathrm{mV}$. However, as shown in Fig. 8b, after coating of chitosan molecule, the zeta potential value of the $\mathrm{Fe}_{3} \mathrm{O}_{4}$-chitosan composite increased to $26.8 \pm 0.87 \mathrm{mV}$. Chitosan can adsorb onto $\mathrm{Fe}_{3} \mathrm{O}_{4}$ nanoparticles easily by electrostatic attraction, and the amino groups generate positive charge on the $\mathrm{Fe}_{3} \mathrm{O}_{4}$ nanoparticles surface, which is similar to that reported previously. ${ }^{52,53}$

The surface morphology of $\mathrm{Fe}_{3} \mathrm{O}_{4}, \mathrm{Fe}_{3} \mathrm{O}_{4}$-chitosan particles and $\mathrm{Fe}_{3} \mathrm{O}_{4}$-chitosan-L-ASNase were confirmed by SEM (Fig. 9). The $\mathrm{Fe}_{3} \mathrm{O}_{4}$ nanoparticles were rough, nearly spherical in shape and aggregated (Fig. 9a-c). After the coating with chitosan, the surface morphology of $\mathrm{Fe}_{3} \mathrm{O}_{4}$ nanoparticles evidently changed. In Fig. 9(b-d), the SEM images confirm the coating process of $\mathrm{Fe}_{3} \mathrm{O}_{4}$ with increasing of the particles size. The results of this experiment were similar to those in previously published papers. ${ }^{54}$ Fig. 9 (e and f) represents the image of $\mathrm{Fe}_{3} \mathrm{O}_{4}$-chitosan particles after bioconjugation. The SEM images revealed that there are differences in the surface micromorphology of $\mathrm{Fe}_{3} \mathrm{O}_{4}-$ chitosan particles. As expected, the size of particles increased after the immobilization procedure.

The surface composition of unmodified $\mathrm{Fe}_{3} \mathrm{O}_{4}$, and $\mathrm{Fe}_{3} \mathrm{O}_{4}-$ chitosan particles was investigated by EDX, as shown in Fig. 10. The EDX map of $\mathrm{Fe}_{3} \mathrm{O}_{4}$ nanoparticles is mainly composed of only iron (Fe) and oxygen (O) elements (Fig. 10a). In addition, no peaks related to other elements were detected, which revealed the high purity of the sample. However, the new signals corresponding to carbon (C) and nitrogen (N) appeared for $\mathrm{Fe}_{3} \mathrm{O}_{4}-$ chitosan (Fig. 10b). Therefore, it can be assumed that chitosan is coated onto the surface of $\mathrm{Fe}_{3} \mathrm{O}_{4}$ nanoparticles.

The magnetic properties of the $\mathrm{Fe}_{3} \mathrm{O}_{4}$ and $\mathrm{Fe}_{3} \mathrm{O}_{4}$-chitosan particles were investigated by VSM analysis at room temperature. As shown in Fig. 11, there is no hysteresis in the magnetization for the two nanoparticles. The saturation magnetization of the bare $\mathrm{Fe}_{3} \mathrm{O}_{4}$ nanoparticles was about 67 emu $\mathrm{g}^{-1}$, while that for $\mathrm{Fe}_{3} \mathrm{O}_{4}$-chitosan particles was about 37 emu $\mathrm{g}^{-1}$ in this experiment. The existence of chitosan on the surface of $\mathrm{Fe}_{3} \mathrm{O}_{4}$ nanoparticles gave rise to the decrease in the uniformity due to quenching of surface moments, resulting in the reduction of magnetic moment in the nanoparticles. ${ }^{55} \mathrm{~A}$ similar decrease in saturation magnetization values were reported by other researchers. In addition, neither coercivity nor

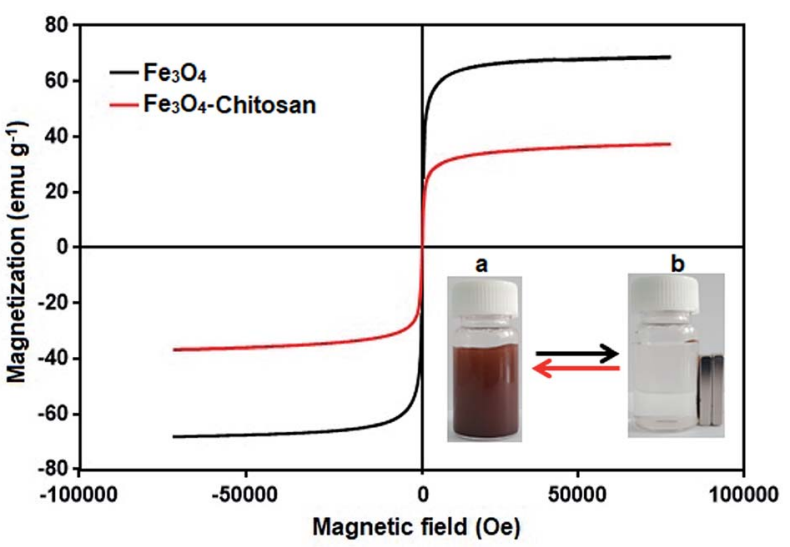

Fig. 11 VSM measurements of the obtained $\mathrm{Fe}_{3} \mathrm{O}_{4}$ and $\mathrm{Fe}_{3} \mathrm{O}_{4}$-chitosan particles. The photographic image of $\mathrm{Fe}_{3} \mathrm{O}_{4}-$ chitosan particles (a) without magnet and (b) with magnet.

remanence was observed, implying that the nanoparticles are almost superparamagnetic. The inset of Fig. 11 shows the photographs of an aqueous solution of $\mathrm{Fe}_{3} \mathrm{O}_{4}$-chitosan particles in the absence of magnetic field and in the presence of externally applied magnetic field.

\subsection{Optimization of conditions on the conjugated L-ASNase}

The efficiency of L-ASNase immobilized on $\mathrm{Fe}_{3} \mathrm{O}_{4}$-chitosan was calculated as $73.2 \%$. This high immobilization efficiency revealed that $\mathrm{Fe}_{3} \mathrm{O}_{4}$-chitosan particles can be a prominent carrier matrix for immobilization of L-ASNase. Moreover, the specific activity of free L-ASNase was $289 \pm 8.4 \mathrm{U} \mathrm{mg}^{-1}$ protein, while the specific activity of conjugated L-ASNase was $179 \pm 4.6$ $\mathrm{U} \mathrm{mg}{ }^{-1}$ protein. This decrease in the specific activity after immobilization may be due to diffusion limitation. Additionally, immobilization of the enzyme by covalent binding would lead to a decrease in the flexibility of the enzyme molecule, which is commonly reflected by a decrease in catalytic activity. ${ }^{56}$

3.2.1 Effect of $\mathbf{p H}$ and temperature. The effect of $\mathrm{pH}$ on $\mathrm{L}^{-}$ ASNase immobilization was studied between $\mathrm{pH}$ values of 4.0 and 10.0. As depicted in Fig. 12a, the maximum enzyme activity of free $\mathrm{L}_{\mathrm{ASN}} \mathrm{Ase}$ is observed at pH 8.0. However, the conjugated L-ASNase displayed maximum enzyme activity at $\mathrm{pH}$ 8.5. Moreover, conjugated enzyme exhibited better $\mathrm{pH}$ tolerance than the free enzyme in acidic or alkaline medium. For instance, the residual activities at $\mathrm{pH} 4.0$ and 10.0 were $43.3 \%$ and $76.14 \%$ for conjugated enzyme, respectively, which were higher than that of free L-ASNase $(12.3 \%$ and $40.6 \%$, respectively) at the same $\mathrm{pH}$ values. In short, the conjugated L-ASNase demonstrated good adaptability to acidic or alkaline environment owing to the $\mathrm{Fe}_{3} \mathrm{O}_{4}$-chitosan carrier surrounding it.

The effect of temperature on the enzyme activity is shown in Fig. 12b. While the optimum temperature for free enzyme was $45{ }^{\circ} \mathrm{C}$, the conjugated enzyme showed maximum activity at $60{ }^{\circ} \mathrm{C}$. The activity of the free enzyme decreased more sharply than that of the conjugated enzyme at higher temperature. Although the free enzyme was readily inactivated at $60{ }^{\circ} \mathrm{C}$, the conjugated L-ASNase maintains more than $60 \%$ of the initial 
activity even at $70{ }^{\circ} \mathrm{C}$. This occurs probably because the immobilization of L-ASNase on the support limited the conformational mobility of the enzyme molecules at high temperature, preventing it from inactivation. ${ }^{57}$ Similar results of improved $\mathrm{pH}$ and temperature adaptability could be observed in other immobilization studies of L-ASNase. ${ }^{58,59}$
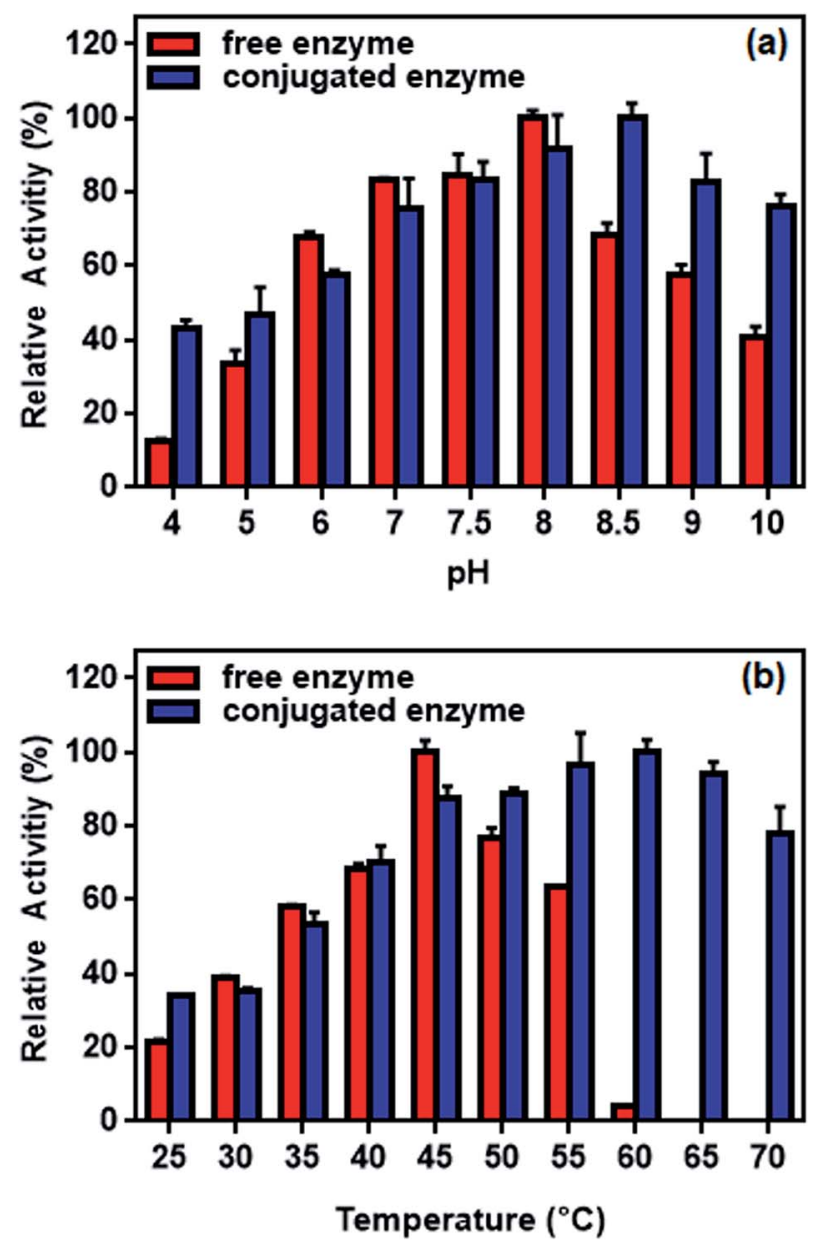

Fig. 12 Relative activity of free and conjugated L-ASNase: (a) at different $\mathrm{pH}$ values and (b) at different temperature.
3.2.2 $\mathrm{pH}$ and thermal stability. The $\mathrm{pH}$ stability of free and conjugated L-ASNase was investigated at acidic (5.0) and alkaline (9.0) $\mathrm{pH}$ values for $180 \mathrm{~min}$ with $30 \mathrm{~min}$ intervals. As shown in Fig. 13a, the conjugated L-ASNase could retain a high degree of activity (more than 62\%) after $180 \mathrm{~min}$ incubation at pH 5.0. Furthermore, it still displayed promising enzymatic activity of about $83 \%$ after $180 \mathrm{~min}$ incubation at $\mathrm{pH}$ 9.0. However, free $\mathrm{L}^{-}$ ASNase exhibited $53.2 \%$ and $73.8 \%$ its initial activity after 180 min incubation at $\mathrm{pH} 5.0$ and $\mathrm{pH}$ 9.0, respectively. These results revealed that L-ASNase exhibits high activity at alkali medium. The conjugated L-ASNase possessed remarkably high stability towards alkali $\mathrm{pH}$, which was beneficial for improving the reaction efficiency.

Thermal stability of the conjugated enzyme is one of the most important criteria with respect to applications. Fig. 13b plots residual activity for the free and conjugated L-ASNase during $180 \mathrm{~min}$ test at $55{ }^{\circ} \mathrm{C}$. The relative activity of conjugated L-ASNase remained higher than that of free L-ASNase at each time interval. The conjugated L-ASNase still retained $84 \%$ of its initial activity after $120 \mathrm{~min}$ incubation, whereas free L-ASNase retained $64 \%$ activity at the same conditions. When the incubation time is $180 \mathrm{~min}$, conjugated enzyme holds approximately $54 \%$ of initial activity, while free enzyme lost almost all of its activity. Thus, the thermal stability of L-ASNase significantly improved after conjugation. Considering the results described above, the enzymatic activity of the conjugated L-ASNase was improved significantly, and it was more stable than the free $\mathrm{L}^{-}$ ASNase, particularly under harsh conditions, as described above.

3.2.3 Kinetic studies. In the present study, the kinetic parameters were measured by using Lineweaver-Burk equation for free and conjugated L-ASNase and reported in Table 1. The $K_{\mathrm{m}}$ value gives an idea about the affinity of an enzyme to its substrate; a decrease in $K_{\mathrm{m}}$ indicates the increase in affinity and

Table 1 Kinetic parameters of the free and conjugated L-ASNase

\begin{tabular}{lll}
\hline & $K_{\mathrm{m}}(\mathrm{mM})$ & $V_{\max }\left(\mathrm{U} \mathrm{mg} \operatorname{protein}^{-1}\right)$ \\
\hline Free L-ASNase & $0.65 \pm 0.078$ & $578.3 \pm 38.0$ \\
Conjugated L-ASNase & $0.14 \pm 0.007$ & $284.7 \pm 12.5$
\end{tabular}
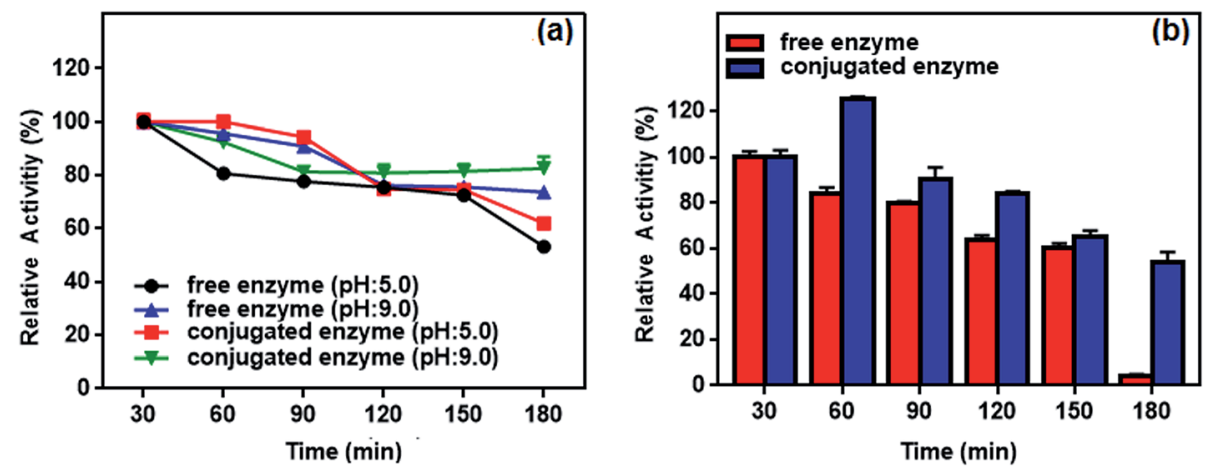

Fig. 13 (a) $\mathrm{pH}$ and (b) thermal stability of the free and conjugated enzyme at different time intervals (30-180 min). 
(a)

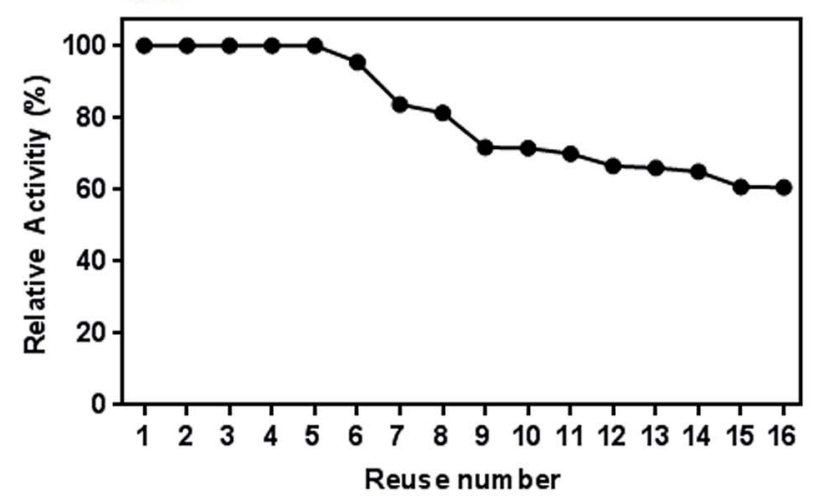

(b)

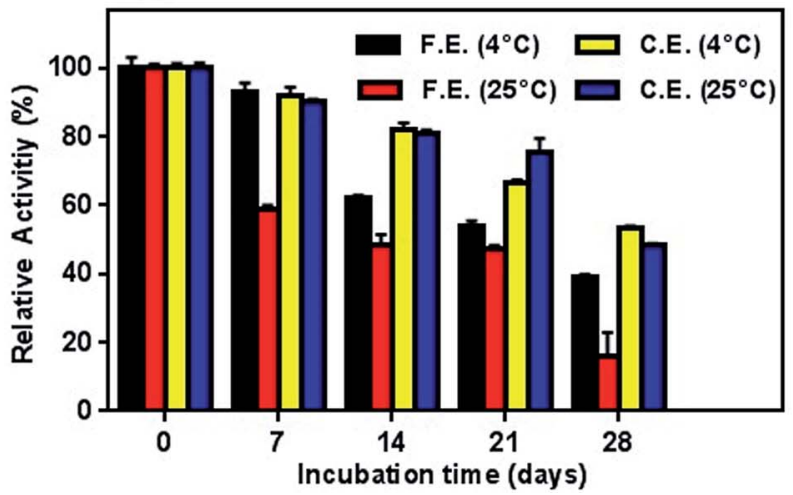

Fig. 14 (a) Profile of reusability test for conjugated enzyme and (b) storage stability of free and conjugated L-ASNase on $\mathrm{Fe}_{3} \mathrm{O}_{4}$-chitosan at $4{ }^{\circ} \mathrm{C}$ and r.t. in dried state.

consequently the enzyme activity. ${ }^{60}$ The calculated $K_{\mathrm{m}}$ values of free and conjugated L-ASNase were 0.65 and 0.14 for L-Asn, respectively. The observed decrease in $K_{\mathrm{m}}$ after immobilization implies that the affinity of the conjugate enzyme to the substrate increased 4.64-fold compared with that of the free enzyme. The values of $V_{\max }$ for free and conjugated L-ASNase were found to be 578.3 and $284.7 \mathrm{U} \mathrm{mg}^{-1}$ protein, respectively. The cause of the decline in $V_{\max }$ may be the restricted diffusion of the substrate and uniform orientation of the enzyme..$^{58,61}$

3.2.4 Reusability and storage stability. To the best of our knowledge, while the free enzymes cannot be easily removed from the reaction medium without being denatured, immobilized enzymes can be easily separated and used as repeatedly.
Therefore, the reusability of the immobilized enzyme is a very important advantage in bio-based applications and plays a key role in its economic significance. ${ }^{57}$ In this study, the conjugated enzyme is highly reusable since the magnetic nanoparticles are easily removed from the reaction medium via an external magnet. The reusability of the conjugated L-ASNase was evaluated through repetitive experiments. As shown in Fig. 14a, the conjugated enzyme retained $100 \%$ of its original enzymatic activity after first 5 cycles and it maintained $60.5 \%$ of its initial activity even after 16 consecutive cycles of reuse. This high reusability of conjugated enzyme indicated that the immobilization method based on functionalized magnetic nanoparticles is successful and will guide future applications.

Similar to reusability, long-time storage of L-ASNase is also a significant parameter to reduce the cost of the enzyme in the industrial applications since free enzyme denatures after a certain period of time. To test the long-term storage stability of enzymes, both the free and conjugated L-ASNase were preserved at $4{ }^{\circ} \mathrm{C}$ and room temperature for 4 weeks. The residual activities were measured as described in the assay section. As exhibited in Fig. 14b, the storage stability of conjugated $\mathrm{L}^{-}$ ASNase was much higher than that of free L-ASNase at $4{ }^{\circ} \mathrm{C}$ and r.t. It could be observed that free L-ASNase retained $39.2 \%$ of the initial activity after 4 weeks, while the conjugated L-ASNase still maintained more than half $(53.3 \%)$ of the initial activity after the same period. Moreover, it was found that the conjugated $\mathrm{L}^{-}$ ASNase retained $48.4 \%$ of its initial activity at r.t. However, the free enzyme only retained $16 \%$ of the initial activity after 4 weeks at the same storage condition. These outcomes illustrated that the storage stability of L-ASNase fairly improved after immobilization with $\mathrm{Fe}_{3} \mathrm{O}_{4}$-chitosan magnetic particles due to increased stabilization of its active conformation by formation of a covalent bond between $\mathrm{Fe}_{3} \mathrm{O}_{4}$-chitosan and L-ASNase molecule.

3.2.5 The effect of magnetic-propelled on conjugated LASNase. The effect of frequency on conjugated enzyme's activity is shown in Fig. 15a. Results showed that the activity of conjugated L-ASNase increased with the increase in the frequency of the applied magnetic field. At $3 \mathrm{~Hz}$, the activity of conjugated LASNase reached maximum (175\%) when compared with that obtained in control experiments without magnetic field. Moreover, application of the magnetic field at high magnetic flux density $(30 \mathrm{mT})$ resulted in an increase of more than $300 \%$ in the enzymatic activity of L-ASNase when compared with that if
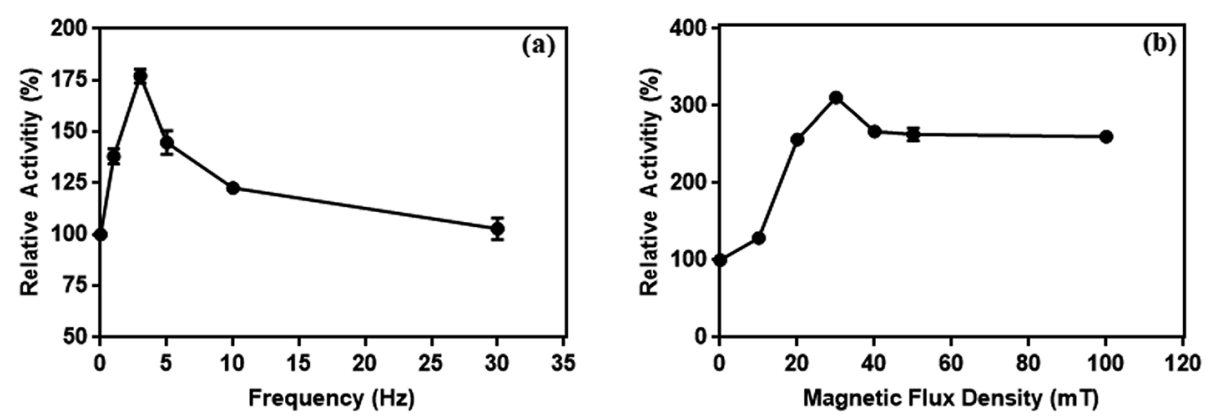

Fig. 15 The effect of frequency at $10 \mathrm{mT}$ (a) and (b) magnetic flux density at $3 \mathrm{~Hz}$ on the enzymes activity conjugated on magnetic particles. 
the control sample that was not exposed to the magnetic field (Fig. 15b). The activity of the free L-ASNase was also determined under the same conditions, but the results are not shown because there were no any changes observed.

It has been reported that a relative increase in the interaction between enzymes and substrate molecules is associated with an increase in activity. In our study, we think that there are two important reasons for the increase in enzyme activity at certain frequency and flux density in the weak magnetic field. First is the effective prevention of the aggregation of L-ASNaseimmobilized particles during the reaction with weak magnetic field. Second, magnetic-propelled enzymes more likely show enzyme-substrate interaction. We also believe that the enzymes are more stable in the covalent modification on the magnetic particle during these processes and this promotes the increase in activity of the immobilized L-ASNase.

\section{Conclusions}

L-ASNase is a unique enzyme for the enzymatic hydrolysis of $\mathrm{L}^{-}$ Asn in medicine and food industry. Nevertheless, its instability, toxicity and poor reusability significantly limit the long-term applications. In order to overcome these disadvantages, for the first time, in this study, chitosan-modified magnetic particles were synthesized and employed for covalent immobilization of L-ASNase to improve its stability and reusability performance. Additionally, we developed a magnetic field platform and successfully studied the effect of magnetic field on conjugated L-ASNase activity. To demonstrate the superiority of the conjugated L-ASNase, we also compared the immobilization parameters when free enzyme was used as a control. The conjugated L-ASNase prepared in this study displayed excellent long-term storage and incubation stability, thermal stability, and reusability as compared with those of the free enzyme. More importantly, the magnetic field experiment results indicated that there was a considerable effect of magnetic exposure on the conjugated L-ASNase. Taking the abovementioned results into consideration, magnetic $\mathrm{Fe}_{3} \mathrm{O}_{4}$-chitosan particles formed with the combination of the inorganic material and natural polymer material could be used as an ideal carrier matrix for $\mathrm{L}^{-}$ ASNase immobilization. Moreover, the application of a static magnetic field can be a promising strategy to increase the enzyme activity, particularly the activity of industrially important enzymes and their broad applications.

\section{Conflicts of interest}

The authors report no declarations of interest.

\section{Acknowledgements}

Authors are grateful to the Inonu University (FDK-2017-751).

\section{Notes and references}

1 A. Ulu and B. Ates, Bioconjugate Chem., 2017, 28, 1598-1610.
2 U. K. Narta, S. S. Kanwar and W. Azmi, Crit. Rev. Oncol. Hematol., 2007, 61, 208-221.

3 R. Pieters, S. P. Hunger, J. Boos, C. Rizzari, L. Silverman, A. Baruchel, N. Goekbuget, M. Schrappe and C. H. Pui, Cancer, 2011, 117, 238-249.

4 T. Mizuki, N. Watanabe, Y. Nagaoka, T. Fukushima, H. Morimoto, R. Usami and T. Maekawa, Biochem. Biophys. Res. Commun., 2010, 393, 779-782.

5 L. T. Prando, P. R. De Lima, K. Rezzadori, J. V. De Oliveira and M. Di Luccio, Ind. Eng. Chem. Res., 2017, 56, 9065-9071.

6 A. Ali, H. Zafar, M. Zia, I. ul Haq, A. R. Phull, J. S. Ali and A. Hussain, Nanotechnol., Sci. Appl., 2016, 9, 49-67.

7 S. Sabale, P. Kandesar, V. Jadhav, R. Komorek, R. K. Motkuri and X. Y. Yu, Biomater. Sci., 2017, 5, 2212-2225.

8 C. Yang, W. Guo, L. Cui, N. An, T. Zhang, H. Lin and F. Qu, Langmuir, 2014, 30, 9819-9827.

9 Y. Wang, J. Dostalek and W. Knoll, Anal. Chem., 2011, 83, 6202-6207.

10 M. An, J. Cui and L. Wang, J. Phys. Chem. C, 2014, 118, 30623068.

11 Y. K. Peng, C. N. P. Lui, Y. W. Chen, S. W. Chou, E. Raine, P. T. Chou, K. K. L. Yung and S. C. E. Tsang, Chem. Mater., 2017, 29, 4411-4417.

12 X. M. Ling, X. Y. Wang, P. Ma, Y. Yang, J. M. Qin, X. J. Zhang and Y. W. Zhang, J. Microbiol. Biotechnol., 2016, 26, 829-836.

13 Y. Liu, S. Jia, Q. Wu, J. Ran, W. Zhang and S. Wu, Catal. Commun., 2011, 12, 717-720.

14 X. Y. Wang, X. P. Jiang, Y. Li, S. Zeng and Y. W. Zhang, Int. J. Biol. Macromol., 2015, 75, 44-50.

15 C. H. Jun, Y. J. Park, Y. R. Yeon, J. Choi, W. Lee, S. Ko and J. Cheon, Chem. Commun., 2006, 0, 1619-1621.

16 Z. Zhang, H. Duan, S. Li and Y. Lin, Langmuir, 2010, 26, 6676-6680.

17 S. A. Adams, J. L. Hauser, A. C. Allen, K. P. Lindquist, A. P. Ramirez, S. Oliver and J. Z. Zhang, ACS Appl. Nano Mater., 2018, 1, 1406-1412.

18 A. Ulu, I. Ozcan, S. Koytepe and B. Ates, Int. J. Biol. Macromol., 2018, 115, 1122-1130.

19 K. Manna and S. K. Srivastava, ACS Sustainable Chem. Eng., 2017, 5, 10710-10721.

20 Y. Lin, X. Liu, Z. Xing, Y. Geng, J. Wilson, D. Wu and H. Kong, Cellulose, 2017, 24, 5541-5550.

21 A. Mohseni-Bandpi, B. Kakavandi, R. R. Kalantary, A. Azari and A. Keramati, RSC Adv., 2015, 5, 73279-73289.

22 A. Ulu, S. A. A. Noma, C. Gurses and S. Koytepe, Starch Stärke, 2018, DOI: 10.1002/star.201700303.

23 J. Guo, Z. Zheng, C. Chen, X. Lu, Y. Zhang and B. Zheng, J. Agric. Food Chem., 2017, 65, 7934-7943.

24 L. Zang, J. Qiu, X. Wu, W. Zhang, E. Sakai and Y. Wei, Ind. Eng. Chem. Res., 2014, 53, 3448-3454.

25 X. Liu, X. Chen, Y. Li, X. Wang, X. Peng and W. Zhu, ACS Appl. Mater. Interfaces, 2012, 4, 5169-5178.

26 J. Long, Z. Wu, X. Li, E. Xu, X. Xu, Z. Jin and A. Jiao, J. Agric. Food Chem., 2015, 63, 3534-3542.

27 H. Suo, L. Xu, C. Xu, H. Chen, D. Yu, Z. Gao, H. Huang and Y. Hu, Int. J. Biol. Macromol., 2018, 119, 624-632.

28 M. M. Bradford, Anal. Biochem., 1976, 72, 248-254. 
29 L. T. Mashburn and J. C. Wriston, Arch. Biochem. Biophys., 1964, 105, 450-452.

30 N. E. A. El-Naggar, H. Moawad, N. M. El-Shweihy and S. M. El-Ewasy, BioMed Res. Int., 2015, 2015, 627031.

31 Y. Haldorai, A. Rengaraj, T. Ryu, J. Shin, Y. S. Huh and Y. K. Han, J. Mater. Sci. Eng. B, 2015, 195, 20-29.

32 J. Qu, G. Liu, Y. Wang and R. Hong, Adv. Powder Technol., 2010, 21, 461-467.

33 H. Qin, C. M. Wang, Q. Q. Dong, L. Zhang, X. Zhang, Z. Y. Ma and Q. R. Han, J. Magn. Magn. Mater., 2015, 381, 120-126.

34 C. Yuwei and W. Jianlong, Chem. Eng. J., 2011, 168, 286-292.

35 L. Y. Zhang, X. J. Zhu, H. W. Sun, G. R. Chi, J. X. Xu and Y. L. Sun, Curr. Appl. Phys., 2010, 10, 828-833.

36 G. Y. Li, Y. R. Jiang, K. L. Huang, P. Ding and J. Chen, J. Alloys Compd., 2008, 466, 451-456.

37 N. F. M. Rodrigues, S. Y. Neto, R. de C. S. Luz, F. S. Damos and H. Yamanaka, Biosensors, 2018, 8(1), 16.

38 C. Pan, B. Hu, W. Li, Y. Sun, H. Ye and X. Zeng, J. Mol. Catal. B: Enzym., 2009, 61, 208-215.

39 P. G. Ingole, N. R. Thakare, K. Kim, H. C. Bajaj, K. Singh and H. Lee, New J. Chem., 2013, 37, 4018-4024.

40 Ö. Aybastier, S. Şahin, E. Işik and C. Demir, Anal. Methods, 2011, 3, 2289-2297.

41 S. Ghosh, S. R. Chaganti and R. S. Prakasham, J. Mol. Catal. B: Enzym., 2012, 74, 132-137.

42 E. Bahreini, K. Aghaiypour, R. Abbasalipourkabir and A. R. Mokarram, Nanoscale Res. Lett., 2014, 9, 340.

43 C. Cao, L. Xiao, C. Chen, X. Shi, Q. Cao and L. Gao, Powder Technol., 2014, 260, 90-97.

44 W. Li, L. Xiao and C. Qin, J. Macromol. Sci., Part A: Pure Appl.Chem., 2011, 48, 57-64.

45 J. A. Ratto, T. Hatakeyama and R. B. Blumstein, Polymer, 1995, 36, 2915-2919.
46 D. de Britto and S. P. Campana-Filho, Thermochim. Acta, 2007, 465, 73-82.

47 M. Mucha and A. Pawlak, Polimery, 2002, 47, 509-516.

48 W. Jiang, W. Wang, B. Pan, Q. Zhang, W. Zhang and L. Lv, ACS Appl. Mater. Interfaces, 2014, 6, 3421-3426.

49 J. Safari and L. Javadian, Ultrason. Sonochem., 2015, 22, 341348.

50 S. F. Shi, J. F. Jia, X. K. Guo, Y. P. Zhao, D. S. Chen, Y. Y. Guo, T. Cheng and X. L. Zhang, Int. J. Nanomed., 2012, 7, 55935602.

51 Y. H. Chen, H. E. Tu and J. Leu, Microporous Mesoporous Mater., 2012, 162, 181-188.

52 G. Cheng and S. Y. Zheng, Sci. Rep., 2014, 4, 6947.

53 A. Zhu, L. Yuan and T. Liao, Int. J. Pharm., 2008, 350, 361368.

54 Y. Liu, S. Jia, Q. Wu, J. Ran, W. Zhang and S. Wu, Catal. Commun., 2011, 12, 717-720.

55 S. Nasirimoghaddam, S. Zeinali and S. Sabbaghi, J. Ind. Eng. Chem., 2015, 27, 79-87.

56 M. A. Abdel-Naby, A. A. Sherif, A. B. El-Tanash and A. T. Mankarios, J. Appl. Microbiol., 1999, 87, 108-114.

57 J. Song, T. Lei, Y. Yang, N. Wu, P. Su and Y. Yang, New J. Chem., 2018, 42, 8458-8468.

58 A. Ulu, S. Koytepe and B. Ates, J. Appl. Polym. Sci., 2016, 133, 19.

59 A. Ulu, S. A. A. Noma, S. Koytepe and B. Ates, Artif. Cells, Nanomed., Biotechnol., 2018, 0, 1-11.

60 S. A. Ahmed, F. A. Mostafa and M. A. Ouis, Int. J. Biol. Macromol., 2018, 112, 371-382.

61 A. Ulu, S. Koytepe and B. Ates, Polym. Bull., 2016, 73, 18911907. 